\title{
THE INFLUENCE OF ORGANIZATIONAL AESTHETICS ON EMPLOYEE RETENTION AND TURNOVER INTENTIONS FROM ORGANIZATION
}

\author{
Iman Sabbagh Molahosseini ${ }^{1}$, Masoud Pourkiani ${ }^{2}$, Farzaneh \\ Beygzadeh Abbasi ${ }^{3}$, Sanjar Salajeghe ${ }^{4}$, Hamdollāh Manzari Tavakoli ${ }^{5}$ \\ ${ }^{I}$ Department of Management, Kerman Branch, Islamic Azad University, Kerman, Iran. \\ E-mail: iman.sabbaghm@gmail.com \\ ${ }^{2}$ Department of Management, Kerman Branch, Islamic Azad University, Kerman, Iran. \\ E-mail:pourkiani@iauk.ac.ir \\ ${ }^{3}$ Department of Management, Kerman Branch, Islamic Azad University, Kerman, Iran. \\ E-mail:farzanehbigzadeh@yahoo.com \\ ${ }^{4}$ Department of Management, Kerman Branch, Islamic Azad University, Kerman, Iran. \\ E-mail: salajeghe_187@yahoo.com \\ ${ }^{5}$ Department of Management, Kerman Branch, Islamic Azad University, Kerman, Iran. \\ E-mail: hmanzari@iauk.ac.ir
}

Received 1401 2020, Accepted 29052020

The present study offered a new perspective on the impact Organizational Aesthetics on employee retention and turnover Intentions from organization. The research approach of this study was a qualitative approach and the grounded theory method has been used. Deep interviewing was used to collect data. The statistical population of this study was employees of the social insurance organization of Kerman city, Iran. The sampling methods of this study consisted of theoretical sampling. Theoretical sampling is one of the basic steps in the process of grounded theory. Besides, the analysis of the data is performed based on the three coding methods used in grounded theory which include open, axial, and selective coding. The results of this study showed that organizational aesthetics strategy cause employee retention. Also, organizational aesthetics strategy prevents employee turnover intentions from the organization.

Keywords: aesthetics, organizational aesthetics, retention, turnover intentions.

JEL Codes: MOO, M10, M54.

\section{Introduction}

The employee's turnover intentions for many organizations is a worrying issue (Goodwin et al, 2011). The turnover intentions are one of the organizational dilemmas that impact, the organization movement and it has become a problem for organization manager who is always looking for maintenance, improvement and productivity of their Manpower (Mamizaeh, 2002). To achieve their goals, organizations must be capable of protecting human resources, attracting, and keeping them. Among the factors that make organization difficult to achieve these goals is the issue of turnover intentions and the desire to turnover intentions (Shahbazi et al, 2008). Turnover intentions of employee's attention from human resource managers and researchers.

Copyright (C) 2020. Published by Vytautas Magnus University. This is an open access article distributed under the terms of the Creative Commons Attribution Non-Commercial 4.0 (CC BY-NC 4.0) license, which permits unrestricted use, distribution, and reproduction in any medium provided the original author and source are credited. The material cannot be used for commercial purposes. 


\section{Iman Sabbagh Molahosseini, Masoud Pourkiani, Farzaneh Beygzadeh Abbasi, Sanjar Salajeghe, Hamdollāh Manzari Tavakoli.}

The Influence of Organizational Aesthetics on Employee Retention and Turnover Intentions from Organization

That is because the cost of turnover intentions on operational capabilities, organization budgets, and organization performance will have a destructive impact (Zhu et al, 2017).a high turnover rate of employees can a negative effect on executives manager performance (Arnold, 2005 ). There are a lot of expenses being imposed on the organization when they lose employees. For example, in Hall research (1998) employers considered the costs of employing the new force from 50 to $60 \%$ of the years' salary. It has also been mentioned that the costs of replacement of talented individuals are higher than $70 \%$ to $200 \%$ of the annual salaries of those employees (Rezaeian et al, 2018). Fitzenz believe that each company loses an average of about 1 million $\$$ with every 10 professionals who leave the organization (Al-Khaled, 2014). Rather, employee service is much more complicated than it seems. In all the concepts and terms of industrial and organizational psychology, two separate definitions have been proposed for it. In the general definition, leaving the service out of the organization and expressing dissatisfaction with the profession and in particular, defined it as a change in an individual's membership in an organization that encompasses a wide range of changes and status change (Mamizaeh, 2002).

Numerous studies have been done on explaining the causes of turnover intentions and the type of impact on each of them. The results showed that there was a relationship between turnover intentions, motivation, job satisfaction and organization commitment (Mamizaeh, 2002).on the other hand, increasing productivity as well as to strengthen their motivation and Retention them that retention means an employer strives to retain desirable employees to accomplish the organization's goals. Employee retention leads to benefits such as customer satisfaction, better service, lower costs and more (Rezaeian et al, 2018). Preservation and retention of competent forces and favorable relations between them are among the fundamental goals of human resource management. Human resource management is the policies and actions needed to accomplish a part of the management task that depends on aspects of employee performance, especially for recruiting, training employees, evaluating performance, rewarding and creating a healthy environment for employees (Akbari, 2009). Strengthening the motivation of the human force, including those that affect the retention of the human force and prevent them from serving. The word motivation is derived from the Latin word mover which means movement. Motivation refers to psychological processes that stimulate, direct and sustain voluntary actions that are goal oriented. Motivation is highly personal and varies from person to person. Work motivation is not constant over time. That is, the motivating factor today will not be the same motivational factor for another year (AlKhaled, 2014). In the workplace, working to create some conditions, or modifying or eliminating other conditions, is effective in motivating employees. The work environment should be designed to promote individuality as well as people's desire to grow and compete. Research shows that paying attention to people's needs in creating the right work environment and providing opportunities for growth and prosperity in pursuit of personal goals will play an important role in job satisfaction. Increasing their effectiveness and efficiency (Gaminians, 2004).

One of the most important humanist theorists, Abraham Maslow, explained motivation according to needs. It is called a state of deficiency and deprivation in the living being. The classified into two general categories: deficiency needs and growth needs. Deficiency needs include physiological or physical needs, the need for security or safety, the need for love and belonging, and the need for selfesteem or respect for oneself. The growth need included: a beautiful understanding, order and harmony, curiosity, passion for knowing, learning, and truth acquisition (Saif, 2008). The need to understand beauty is one of the needs of growth, which leads to motivation at work. The concept of beauty has long been one of the topics discussed in various fields of research including philosophy, aesthetics, history, and sociology. Contemporary classical philosophers such as Plato, Aristotle, Kant, Hume, Hegel, Schopenhauer, Nijey, Davy, Schiller, and Heidegger have contributed significantly to the logic of aesthetics (Ivanaj et al, 2018). In the area of aesthetics, there is a literature stream that focuses on art in 
the organization. Finn (1990): Suggested: Art can represent company values and help enrich employees' lives and enhance their appreciation of the organization. Although aesthetics as the subject of philosophical research dates to several centuries, it is only in the past few decades that more aspects of our reality are emerging, and that our social reality is more and more aesthetic. Welsch (1996): He points to several aesthetic processes happening around us. We love living in stylish homes, owning beautiful cars, going to the store and setting out to buy aesthetic standards. In other words, we create our urban, industrial and natural environment with an aesthetic scenario (Weggeman, et al, 2007).

The aesthetics of the organization have been identified as an important area of the organization( Hancock, 2003). Aesthetics is a new way of working, a leadership style, a form of communication with others in the workplace (appearance and specificity of the workplace), and artifacts produced in the organization, and symbolic elements of an organization's image. The idea of an aesthetic approach to corporate life and organizational performance appeared in the 1990s thanks to the work of leading scholars such as Alvson and Berg (1992) Weitz et al. (2003), Ramirez (1991-1996), Stratey (1992 2002), Taylor and Hansen (2005) (Ivanaj et al, 2018). Organizations that are not even active in the arts can benefit from applying the organizational aesthetic approach. For example, The Wachter Company, which focuses on personal health and lifestyle management and has become a multinational company and has achieved many successes so far. Stenström (2007) attribute the success of the Whitewater Company to aesthetics, with a focus on the physical and physical characteristics and characteristics of employees in organizational life. However, the aesthetic attitude is focused on both the physical and emotional aspects of individuals, especially employees( Bathurst, 2007).Various researches have been done on the factors affecting employee retention and turnover intentions, but so far no comprehensive research has been conducted on the impact of the organizational aesthetics role on employee Retention and turnover Intentions. For this purpose, the grounded theory is used. Grounded theory is one of the qualitative research strategies on which the theory is based on the basic concepts of the data (Danaeifard et al, 2008).

In this study, researchers are interested in investigating the impact of the role of organizational aesthetics on the Retention and Turnover Intentions employees in the insurance organization. Researchers seek to answer the question of whether organizational aesthetics affect the Retention and Turnover Intentions of employees.

\section{Research method}

The research method used in this research is the grounded theory method. The grounded theory is a research project in sociology in which the researcher deduces a general theory through the abstraction of a process, practice, or interaction based on the participants' views (Creswell, 2017). The statistical population of this study was employees of the insurance organization of Kerman city, Iran. In most research methods, sampling is the first step in the research process, in which sampling is done simultaneously with other aspects of the research. Such a feature is related to the general logic of the research. This is known as theoretical sampling (Roman et al, 2017). Theoretical sampling continues until the theoretical saturation is reached. The theoretical saturation means that no further new data related to the phenomenon of the phenomenon is created. Interviews were conducted with 24 employees of social insurance organization of Kerman city, Iran. Which resulted from 24 theoretical saturation interviews, and the researcher stopped the interview. Semi-structured in-depth interviewing is used to collect the data, and in-depth interviewing is the basic of the grounded theory. In this way, the interviewee gives the interviewee more opportunity to lead the conversation (Ansari Renani et al, 2009). Charmaz (2006) emphasized that interviewing is a good tool for gathering information in field theory. Because it creates interaction between the interviewer and the interviewee, and the interviewer shares his / her roles, 
Iman Sabbagh Molahosseini, Masoud Pourkiani, Farzaneh Beygzadeh Abbasi, Sanjar Salajeghe, Hamdollāh Manzari Tavakoli.

The Influence of Organizational Aesthetics on Employee Retention and Turnover Intentions from Organization

responsibilities, feelings, beliefs, motivations and interests with the interviewer (Gehrels, 2013). Reference to documents is one of the main sources of data collection (Imam Jomezadeh et al, 2015). In terms of time, this research started in 2018 and ended in 2019.

\section{Method of implementation and data analysis}

The grounded theory has a fixed way of analyzing data. The data analysis process has three coding steps. The coding steps in the grounded theory include open coding, axial and selective. In open coding, the notes that the researcher made from the interviews are transformed into smaller pieces as concepts (Newman, 2012). Concepts are meaningful units with specific patterns that include individual thoughts, feelings, and actions (Alvinius et al, 2016). At the axial coding stage, the concepts are categorized or categorized. In this step, we categorize or classify the concepts created from the data (Howard, 2016). These categories include 1 - Causal conditions (causes of the main phenomenon), 2 - strategy, 3Intervening conditions (specific contextual conditions affecting strategy), 4- Contextual conditions (General Conditions Affecting Strategies) and consequence (by the use of strategy) (Najafi et al, 2016). In the third stage, one category is known as the nuclear category, and the other category is linked to this category and eventually the data theory of the foundation is created (Newman, 2012).

Central category. The main category in the aesthetic model of the organization is the desire for beauty in the staff. Causal condition. Beauty emotions, beauty perception, beauty value, beauty experience, beauty need, beauty judgments. Strategies. Organizational Aesthetics is the key strategy for controlling, managing, responding and responding to the aesthetic desire of employees. Intervening conditions. The body image and appearance characteristics of specific conditions affecting the organizational aesthetics were identified. Contextual conditions. Physical environment of the organization General conditions affecting the organizational aesthetics were identified. Consequence. Employee's retention and prevents employee's turnover intentions from the organization.

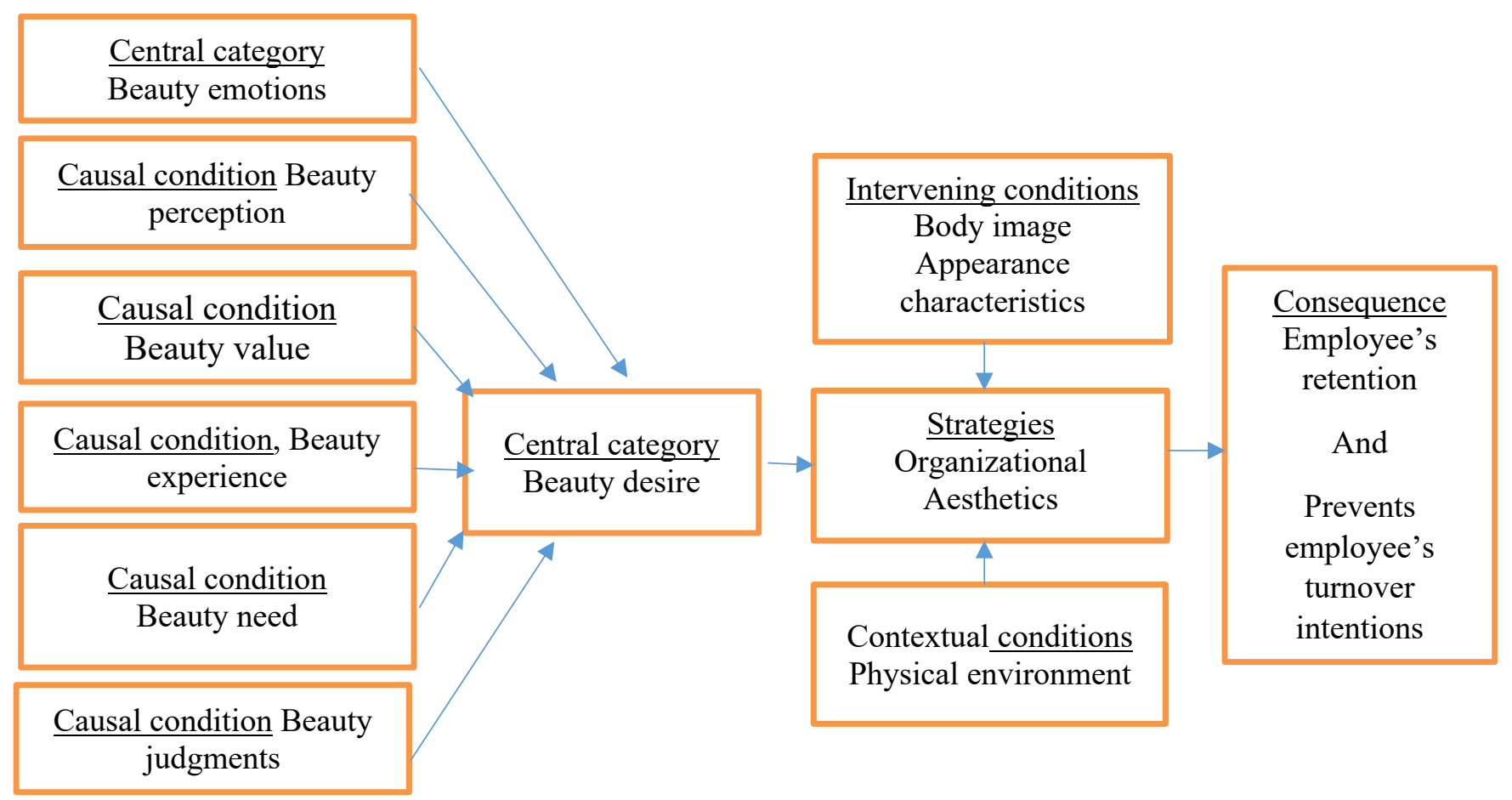

Figure 1. The Organizational Aesthetics Model (Sabbagh Molahossini et al, 2019) 


\section{Results}

The results of the research showed that the desire for beauty in employees was central to the aesthetic model of the organization. Beauty is the most pleasing phenomenon of being and the perception of beauty is one of the most important spiritual privileges of man (Yusufian, 2001). The tendency for beauty is a need and therefore a motivational factor, according to Maslow's hierarchy theory. Needs include physical needs, security needs, love need, respect for self and need for self-perfection (Alvani, 2007). According to the research participants: Beauty emotions, beauty perception, beauty value, beauty experience, beauty need, beauty judgments From Ali's point of view, it creates the central category of aesthetic tendency of Kerman employees in the aesthetic model of organization Organizational Aesthetics, It is the only interaction strategy to respond to the aesthetic desire of employees. According to the grounded theory, the intervening and contextual conditions influence the Organizational Aesthetics strategy. The intervening or specific conditions affecting the aesthetic strategy of the organization are included: Body image and Appearance characteristics. Body image is a mental image of our body that affects our cognitive function, mental health, and physical health. Most of the research on body image in clinical psychology (Rud and Lennon, 2001). Body image is related to how people (whether male or female) understand and feel about their body and how their body image changes throughout their lives (Şanlier, et al., 2016), although individuals have a negative attitude toward their bodies. Whether this causes or causes depression, the prevalence of obesity (Şanlier, et al., 2016). Respondents said having fitness, not being overweight, beautiful face, beautiful smile, speaking tone are among the physical or body-related factors that have been mentioned in numerous researches by researchers. Appearance characteristics of employees are also specific conditions affecting the aesthetics of the organization. Uniforms in the organization play an important role in the perception of employees and clients. It is also effective in enhancing employees' job satisfaction and performance (Frith and Gleeson, 2004). The physical environment of the organization is one of the pervasive or Contextual conditions affecting the Organizational Aesthetics strategy. The physical environment includes all material objects, organization building, furniture, equipment, and environmental conditions such as light and air quality inside the organization (Elsbach and Pratt, 2007). Finally applying Organizational Aesthetics strategy cause employee retention. Also, organizational aesthetics strategy prevents employee's turnover intentions from the organization.

\section{Conclusion}

The purpose of this study investigated the role of organizational aesthetics on employee retention and turnover intentions from the organization. The research was based on grounded theory. The grounded theory is introduced as a strategy. In other words, this research approach, due to its important features, has become a research method in modern sociological research (Bakker, 2019).

According to this theory, central to the Organizational Aesthetics model is the tendency or desire for beauty in employees. In the organization, a set of factors affect the central category of desire, beauty, and cause that desire in employees to be classified as causal factors. Including Beauty emotions, beauty perception, beauty value, beauty experience, beauty need, and beauty judgments. Organizational aesthetics as a unique strategy to treat, manage and control the desire for beauty in the staff. This strategy is influenced by Intervening and Contextual conditions. Intervening conditions Include body image, appearance characteristics and contextual conditions are the physical environment of the organization, and ultimately, the consequence of applying this strategy in the organization is to Employee's retention and prevent employee's turnover intentions from the organization. 


\section{Iman Sabbagh Molahosseini, Masoud Pourkiani, Farzaneh Beygzadeh Abbasi, Sanjar Salajeghe, Hamdollāh Manzari Tavakoli.}

The Influence of Organizational Aesthetics on Employee Retention and Turnover Intentions from Organization

Numerous researches have been carried out by researchers in this field, including: The research cited by Rezaian et al (2018). The research cited indicators that led to staff retention, such as developing and nurturing talent, replacing empirical development, creating equal opportunities for financial dependency growth. In a study conducted by McEvoy\& Henderson 2012, the purpose of this study was to investigate factors affecting the retention of staff close to retirement.

The results of their research showed that flexible work plans, more money, empowerment, more independence, and more opportunities to develop skills and knowledge can potentially impact staff retention. In a 2008 study, Shahbazi et al. identified the factors that influence employee turnover. Three types of factors influence employee turnover. These are environmental variables (Environmental opportunity) individual variables (general education, job involvement) and structural variables (independence, distributive justice, job stress, pay, promotional opportunities and social support).

Much of the research to date has been on Employee's retention and prevent employee's turnover intentions from the organization. Factors such as paying more, flexible work schedules and financial dependency have not been addressed, and no attention has been paid to beauty. According to Maslow's theory, beauty is a motivational need, and aesthetics of the organization is a unique strategy to control, manage, manage and satisfy this basic need in employees.

The results of this research provide new horizons and perspectives for managers of organizations. Overall, it can be said that the aesthetic phenomenon of the organization offers many benefits to organizations. Therefore, organizations should look for ways to create aesthetics in the workplace, and by improving the internal environment and paying attention to the behaviors, appearance and coverage of employees within the organization, this phenomenon should occur. This research was carried out in the insurance organization of Kerman city, Iran. Future researchers are advised to: Do similar research to other organizations to compare the results and increase the validity of the findings.

\section{References}

Arnold, E. (2005). Managing human resources to improve employee retention // The Health Care Manager, Vol. 24(2), pp. 132-140.

Al-Khaled, D. (2014). The Effects of Human Resource Management Practices on Employees' Motivation and Retention.

Alvinius, A. Starrin, B. and Larsson, G. (2016). Becoming a Swedish military ranger: A grounded theory study // Norma, Vol. 11(1), pp.34-51.

Ansari Renani, AH. Tonkejad, M. (2009). Designing an Employee Capabilities Model Using Contextual Theory // Journal of Industrial Management Studies. Year 6, p. 15.

Alvani, M. (2007). General Management. Tehran: Ney Publishing.

Akbari, L. (2009). Human Resource Management, p. 211.

Bathurst, R.( 2007). Aesthetic Leadership: Managing Fields of Flow in Art and Business // Organization Management Journal, Vol. 4(2), pp. 170-174.

Bakker, J. I. (2019). Grounded Theory Methodology and Grounded Theory Method: Introduction to the Special Issue. // Sociological Focus, 52(2), pp. 91-106. publications.

Creswell, J.W (2017). Research design: Qualitative, quantitative, and mixed methods approaches. Sage

Danaeifard, H. Alvani, M.Azar, a (2008). The methodology of quantitative research in management.Tehran, Saffar Press

Elsbach, K. D., Pratt, M. G. (2007). 4 the physical environment in organizations // The academy of management annals, Vol. 1(1), pp.181-224. 
Frith, H., Gleeson, K. (2004). Clothing and embodiment: Men managing body image and appearance // Psychology of Men \& Masculinity. Vol. 5(1), p. 40.

Goodwin, R. E., Groth, M., Frenkel, S. J. (2011). Relationships between emotional labor, job performance, and turnover // Journal of Vocational Behavior, Vol. 79(2), pp.538-548.

Gaminian, V. (2004). Ways to Increase Employee Motivation in the Workplace and Workplace, p. 58.

Gehrels, S. (2013). Grounded theory application in doctorate research // Research in Hospitality Management, Vol. 3(1), pp. 19-25.

Hancock, P. (2003). Aestheticizing the world of organization-creating beautiful untrue things. In Art and aesthetics at work. Palgrave Macmillan UK, pp.174-194.

Howard-Payne, L. (2016). Glaser or Strauss? Considerations for selecting a grounded theory study. // South African Journal of Psychology, Vol. 46(1), pp. 50-62.

Ivanaj, V., Srivastava, P., \& Ivanaj, S. (2018). The value of beauty for organizations // Journal of Cleaner Production, Vol. 189, pp. 877-864.

Imam Jomezadeh, Q. Mehrabi Koushaki, R. (2015). Political Trust Model with Emphasis on Imam Khomeini's Perspective Using Field Theory // Journal of Islamic Revolution Studies. Vol. 12, No. 42, pp. 117138.

Mamizaeh, G. (2002). Leaving the Service to investigate the causes, complications, and consequences. Management Development, p. 44.

McEvoy, G. M., Henderson, S. (2012). The retention of workers nearing retirement: A job embeddedness approach // Journal of Workplace Behavioral Health, Vol. 27(4), pp. 250-271.

Najafi, H. Khaliq Khah, A. Talabi, M. (2016). Investigating the Reasons of Conflicting Behaviors in Organizations for Presenting the Theory Foundation Data Theory. // Journal of Modern Advances in Behavioral Sciences.Vol. 59, p.74.

Newman, D. S. (2012). A grounded theory study of supervision of preservice consultation training // Journal of Educational and Psychological Consultation, Vol. 22(4), pp.247-279.

Rudd, N. A., \& Lennon, S. J. (2001). Body image: Linking aesthetics and social psychology of appearance // Clothing and Textiles Research Journal, Vol. 19(3), pp. 120-133.

Rezaeian, A. Kazem Sedaei, M. Qerecheh, M. Haji Karimi, A. (2018). Identifying Indices of Attraction, Maintenance and Maintenance of Personnel Able in the Banking Industry.

Roman, D.J. Osinski, M. Erdmann, R.H. (2017). The construction process of Grounded Theory in administration. Contaduría y Administración.

Sabbagh Molahosseini, I. Pourkiani, m. Beygzadeh Abbasi, f. Salajeghe, S.and Manzari Tavakoli,H.(2019). The effect of organizational aesthetics on self-esteem, mental health and Morale in employees. Journal of Gurukul Business Review.15, pp.53-60.

Şanlier, N., Türközü, D., Toka, O. (2016). Body image, food addiction, depression, and body mass index in university students. Ecology of food and nutrition, Vol. 55(6), pp. 491-507.

Weggeman, M. Lammers, I. Akkermans, H. (2007). Aesthetics from a design perspective // Journal of Organizational Change Management, Vol. 20(3), pp. 346-358.

Yusufian, G. (2001). Faculty of Literature and Humanities, Tabriz, pp. 135 - 179.

Zhu, X., Seaver, W., Sawhney, R., Ji, S., Holt, B., Sanil, G. B., Upreti, G. (2017). Employee turnover forecasting for human resource management based on time series analysis. // Journal of Applied Statistics, Vol. 44(8), pp.1421-1440. 